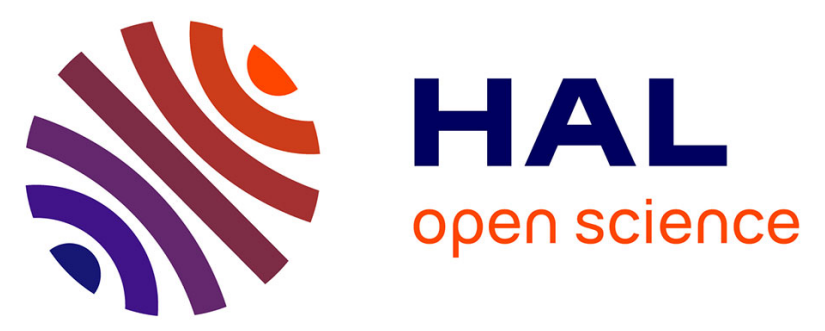

\title{
The influence of temperature during water-quench rapid heat treatment on the microstructure, mechanical properties and biocompatibility of $\mathrm{Ti}[\mathrm{sbnd}] 6 \mathrm{Al}[\mathrm{sbnd}] 4 \mathrm{~V}$ ELI alloy
}

J.A. Chafino, K. Yamanaka, F. Mercier, P. Rivory, S. Balvay, D.J. Hartmann, A. Chiba, D. Fabregue

\section{To cite this version:}

J.A. Chafino, K. Yamanaka, F. Mercier, P. Rivory, S. Balvay, et al.. The influence of temperature during water-quench rapid heat treatment on the microstructure, mechanical properties and biocompatibility of $\mathrm{Ti}[\mathrm{sbnd}] 6 \mathrm{Al}[\mathrm{sbnd}] 4 \mathrm{~V}$ ELI alloy. Journal of the mechanical behavior of biomedical materials, 2019, 96, pp.144-151. 10.1016/j.jmbbm.2019.04.024 . hal-02405430

\author{
HAL Id: hal-02405430 \\ https://hal.science/hal-02405430
}

Submitted on 22 Oct 2021

HAL is a multi-disciplinary open access archive for the deposit and dissemination of scientific research documents, whether they are published or not. The documents may come from teaching and research institutions in France or abroad, or from public or private research centers.
L'archive ouverte pluridisciplinaire HAL, est destinée au dépôt et à la diffusion de documents scientifiques de niveau recherche, publiés ou non, émanant des établissements d'enseignement et de recherche français ou étrangers, des laboratoires publics ou privés.

\section{(ㄷ)(1) $\$$}

Distributed under a Creative Commons Attribution - NonCommerciall 4.0 International 


\title{
The influence of temperature during water-quench rapid heat treatment on the microstructure, mechanical properties and biocompatibility of Ti-6Al-4V ELI alloy
}

J.A. Chafino ${ }^{\mathrm{a}}$, K. Yamanaka ${ }^{\mathrm{b}}$, F. Mercier ${ }^{\mathrm{a}}$, P. Rivory ${ }^{\mathrm{c}}$, S. Balvay ${ }^{\mathrm{c}}$, D.J. Hartmann ${ }^{\mathrm{c}}$, $5 \quad$ A. Chiba ${ }^{\text {b }}$ D. Fabregue

aUniv Lyon, INSA-Lyon, MATEIS, UMR CNRS 5510, 20 Avenue Einstein, 69621

Villeurbanne, France

'Institute for Materials Research, Tohoku University, 2-1-1 Katahira, Aoba-ku, Sendai 9808577, Japan

\begin{abstract}
This study investigates the influence of a rapid heat treatment followed by waterquenching on the mechanical properties of Ti-6Al-4V ELI alloy to improve its strength for use in implants. Prior to the experiment, a dilatometry test was performed to understand the progressive $\alpha$ - to $\beta$-phase transformation taking place during heating. The results were then used to carry out heat treatments. Microstructure was analysed using SEM, EBSD, EDX and XRD techniques. Vickers micro-hardness, tensile and high cycle rotating bending tests were used to analyse the influence of the \$lalpha'\$phase fraction on the strength of the studied alloy. Results show that this process can provide a Ti-6Al-4V ELI alloy with a better Yield Strength (YS)/uniform deformation $\left(\varepsilon_{\mathrm{u}}\right)$ ratio and improved high cycle fatigue strength than those observed in the current microstructure used in medical implants. Lastly, cytotoxicity tests were performed on two types of human cells, namely MG63 osteoblast-like cells and fibroblasts. The results reveal the non-toxicity of the heat-treated Ti-6Al-4V ELI alloy. Keywords: Biomaterial, Ti-alloy, Ti-6Al-4V, ELI, Phase Transformation, Martensite, $\alpha^{\prime}$-phase, Dilatometry, Microstructure, Mechanical Properties, Fatigue, Cytotoxicity. 2010 MSC: 00-01,99-00
\end{abstract}

30

Preprint submitted to Journal of Information Processing and Management 


\section{Introduction}

Titanium has exhibited high biocompatibility in laboratory tests since the outset of the titanium industry in 1940 [1, 2, 3]. Initially designed for use in the turbine blades of aircraft jet-engines, the Ti-6Al-4V alloy and its derivate ELI (Extra Low Interstitial) grade were rapidly recognized for their balanced combination of mechanical properties and their excellent biocompatibility and were rapidly adopted by the ASTM (American Society for Testing Materials) as a standard material for biocompatibility applications [4].

The equiaxed microstructure (which offers high strength and good ductility) required by the ASTM norm for biomedical applications is already provided by the microstructure optimization of this alloy, which was designed for use in aeronautical structures with relative high temperatures of $>400^{\circ} \mathrm{C}$. Nevertheless, an improvement in the mechanical properties of Ti-6Al-4V has always been desired. Researchers have studied how the equiaxed microstructure can be refined to improve its mechanical properties. Costly and complicated processes can be used to obtain a smaller microstructure, the so-called UFG (Ultra Fine Grain) microstructure. L.R. Saitova et al. used the ECAP (Equal Channel Angular Pressing) technique to produce the desired UFG equiaxed microstructure in Ti-6Al-4V ELI [5, 6], and obtained an improvement of $9 \%$ in the HCF (High Cycle Fatigue) strength compared to the initial microstructure. Using a different technique, S. Zherebtsev et al. produced the desired UFG microstructure through multiaxial forging, increasing the HCF strength of the Ti-6Al4V ELI alloy by $15 \%$ [7].

Ti-6Al-4V alloy is an extremely versatile material due to its ability to change its microstructure and consequently its mechanical properties. In addition to the equilibrium phases ( $\alpha$ and $\beta$ ), this alloy is able to form metastable phases such as the hexagonal martensite $\left(\alpha^{\prime}\right)$. However, the time during which this phase can be studied is limited by the ASTM standard and the decomposition of the alloys at moderate temperatures.

R.G. Sherman et al. presented the first results showing possible use of the martensite phase to improve the mechanical properties of this alloy. Their work shows that unlike martensite in steels, the presence of $\alpha^{\prime}$-martensite in titanium results in a high-strength and ductile material [8]. M.A. Imam et al. identified the use of water-quench heat 
treatment after $10 \mathrm{~min}$. at $900^{\circ} \mathrm{C}$ as the most appropriate treatment to obtain a fourfold improvement in torsion fatigue properties compared to those obtained in the annealed state, previously thought to possess the best fatigue performance [9]. Authors claimed that the fatigue improvement was due to a TRIP (Transformation Induced Plasticity) deformation mechanism from a retained $\beta$-phase in the martensite phase. The microstructure of this optimized heat treatment was composed of a mixture of $50 \%$ of $\alpha_{\mathrm{p}}, 25 \%$ of $\alpha^{\prime}$ and $25 \%$ of $\beta$. J.R. Kennedy carried out a similar study to that of M.A. Imam et al. In his study, a $1 \mathrm{hr}$ heat treatment was carried out on three samples of different sizes. One of the most relevant results was the non-reproducibility of heat treatments for the different sample sizes in terms of mechanical properties, although an improvement of fatigue strength was obtained in comparison with its annealed state. J.R. Kennedy also explained the fatigue improvement by a TRIP deformation mechanism, even if the XRD measurement on the quenched samples did not detect the retained $\beta$-phase.

Most recently, C. Formanoir et al. also proposed martensite as a suitable method to increase the mechanical properties of Ti-6Al-4V produced by EBM (Electron Beam Melting) [10]. In this study, small samples were treated for $2 \mathrm{hrs}$ before quenching. As a result, the work hardening of almost all samples was improved. The effect of martensite on the cold-rolling ability of Ti-6Al-4V has also been reported by $\mathrm{H}$. Matsumoto et al. [11, 12].

To conclude this review of the previous results found in literature, the high potential of $\mathrm{Ti}-6 \mathrm{Al}-4 \mathrm{~V}$ martensite to optimize mechanical properties is therefore evident. However, it was hard to draw clear conclusions due to discrepancies in the results. Despite the different proposals on the interest of the $\alpha$ '-phase, a systematically study of the influence of phase fractions on static and dynamic mechanical properties has not been performed to date.

It should also be noted that titanium and its alloys possess low thermal conductivity; for this reason, the heating time and sample size acutely influence the resulting properties and lead to the observation of the discrepancies in the bibliography results.

In this study, rapid heat treatment was applied to the Ti-6Al-4V ELI alloy, leading to a dual-phase microstructure after quenching. The resulting microstructure and its mechanical properties were subsequently measured. 


\section{Materials and methods}

The material used in this investigation is an ELI grade Ti-6Al-4V alloy (for composition, see Table 1). Its composition respects the ASTM F136 standard for surgical applications [4]. The $\alpha+\beta$ microstructure, described in Figure 1, is the result of an annealing treatment at $704^{\circ} \mathrm{C}$ for two hours, followed by air cooling after a rolling process. The average grain size is $1.15 \mu \mathrm{m}$ and $0.28 \mu \mathrm{m}$ for the $\alpha$ - and $\beta$-phases, respectively. The product certification indicates $\beta$-transus at $973^{\circ} \mathrm{C}$.

The dilatometry test used to study the phase transformation during heating was carried out on a Gleeble 3500 coupled to a mechanical extensometer. The schematic sample dimensions used for testing is presented in Figure 2. A type-K thermocouple was used to control the $20^{\circ} \mathrm{C} / \mathrm{min}$ heating and cooling rate of the specimen. The sample was heated to $1050^{\circ} \mathrm{C}$, exceeding the $\beta$-transus temperature. To avoid oxidation and nitrogen diffusion, which both cause great change in phase transformations and mechanical properties in titanium alloys [13], the whole test was performed under argon atmosphere after a previous vacuum.

Once the experimental plan had been designed, the heat treatments were carried out using a muffle furnace under argon atmosphere. Three different temperatures were tested, leading to three different phase fractions: $923^{\circ} \mathrm{C}, 948^{\circ} \mathrm{C}$ and $1030^{\circ} \mathrm{C}$.

The first microstructure analysis was carried out using XRD (X-Ray Diffraction). A PANanlytical X'Pert X-ray diffractometer equipped with a monochromator detector and a $1 / 32^{\circ}$ slit was used to analyse a range between $34^{\circ}$ and $42^{\circ}$. Scan parameters were set to a step size of 0.002 and an acquisition rate of 600s/step.

The microstructures of the initial and heat-treated samples were imaged using a Backscattered Electron (BSE) detector and an Electron Backscatter Diffraction (EBSD) detector (NordlysF+ model from Oxford Instruments) in a Zeiss Supra 55 Scanning Electron Microscope (SEM) operated at an accelerating voltage of 20kV. Following a Monte Carlo simulation showing that absorption is lower at this voltage than the $\beta$ grain size for this experimental set up, EDS (Energy Dispersive X-ray Spectroscopy) evaluation was carried out at a voltage of $8 \mathrm{kV}$.

The Vickers micro-hardness test was performed on a Buehler Micromet 5140 machine. Indentation was achieved by applying a $1 \mathrm{~kg}$ load for $10 \mathrm{~s}$ (10 measures per sample). 
An Instron 5967 tensile machine, equipped with an optical extensometer, was used to test three samples for each condition at a displacement rate of $0.2 \mathrm{~mm} / \mathrm{s}$. Samples were machined using the EDM (Electron Discharge Machining) technique, according to the diagram presented in Figure 3.

Rotating bending fatigue tests were carried out on a Walter+Bai UBM 5-200Nm. A fully reversed $(R=-1)$ test was performed at $50 \mathrm{~Hz}$ on the high cycle fatigue range $\left(10^{7}\right.$ cycles), testing 10 samples from each condition. A diagram of the fatigue sample design is shown in Figure 4.

A colorimetric MTT assay was used to assess cytotoxicity on two different human cell types (obtained from adult skin explants), namely MG-63 osteoblast-like cells and the fibroblast. The cells were cultured in 24-well plates, with RPMI 1640 (Dutscher, France, ref L0498-500) supplemented with 10\\% of foetal bovine serum (ref Dutscher, France, ref P040637100) and 5\% of antibiotic/antimycotic solution (ref Dutscher, France, ref SV30079.01) at $37^{\circ} \mathrm{C}$ in a humidified atmosphere of $5 \% \mathrm{CO}_{2}$.

The discs of the studied material were sterilised by ethanol $701 \%$ bath during 30min, rinsed with distilled water and dried. Then the discs were placed in the well of 24-well plate (Corning USA ref 3524) (one sample per well). Finally, the tested material was compared to the control group (culture dish surface - polystyrene treated for cell culture). $100 \mu \mathrm{L}$ of cells suspension were directly deposited on disc of the studied material, with exactly 250,000 cells/mL of MG-63 osteoblast-like cells and 300,000 fibroblasts $/ \mathrm{mL}$. The samples thus seeded were then incubated in a humid atmosphere for $2 \mathrm{hrs}$ at $37^{\circ} \mathrm{C}$ and $5 \% \mathrm{CO}_{2}$ to allow cell adhesion before the addition of $2 \mathrm{~mL}$ of culture medium, for culture until first cytotoxic test at D3.

Each material was evaluated in triplicate and each test was replicated three times.

The cytotoxicity evaluation was performed through a colorimetric MTT assay: yellow salt of tetrazolium was reduced by NAD $(\mathrm{P}) \mathrm{H}$-dependent cellular oxidoreductase enzymes to insoluble Formosan of purple colour. After lysis of cells and solubilisation of crystals of Formosan by DMSO, optical density was measured using an INFINITE F 200 Pro fluorimeter (Tecan) to wavelength of 570nm. The DO was directly proportional of number of living cells present in the well. 


\section{Results \& Discussion}

A dilatometry test was performed prior to the design of the heat treatments carried out in this study. Due to the different crystallography of aand $\beta$-phase, the phase transformation is accompanied by a change in volume. The dilatometry test allows us to quantify the $\alpha / \beta$ phase transformation during heating. The martensitic phase results from the diffusionless transformation of the high temperature $\beta$-phase; the equivalent martensitic phase fraction can therefore be calculated using the dilatometry data. The resulting dilatometry curve is shown in Figure 5.

It should be noted that the dilatometry technique only quantifies the $\alpha / \beta$ transformation. It is thus necessary to take the initial $\beta$-phase fraction into account to correctly evaluate changes in the $\beta$-phase during heating. Microscopic analysis was used to obtain this value.

A BSE detector was used to identify the different chemical compositions of each phase. As the $\beta$-phase is richer in vanadium than the $\alpha$-phase, it appears brighter than $\alpha$-phase, as shown in Figure 6a. The initial $\beta$-phase fraction was also determined by EBSD (Figure 1) to compare the results.

The $\beta$-phase fraction was also calculated using image software analysis. Analysis using BSE images calculated the average of 3 zones and concludes that the initial microstructure is composed of $6 \% \beta$-phase, compared to $4 \%$ when the EBSD technique is used. The initial $\beta$-phase fraction was therefore considered to be an average of $5 \%$ in order to allow for the possible errors of both methods.

The dilatometry curve shows three different distinct zones:

1. From room-temperature to approximately $6000 \mathrm{C}$, a linear behaviour appears that corresponds to the thermal expansion of $\alpha+\beta$ initial microstructure.

2. From $600^{\circ} \mathrm{C}$ to $980^{\circ} \mathrm{C}$, a drastic change occurs, corresponding to $\alpha$ - to $\beta$-phase transformation.

3. At temperatures over $980^{\circ} \mathrm{C}$, a linear behaviour corresponding to $\beta$-phase thermal expansion is restored.

These distinct zones make it possible to apply the Lever rule (see Figure 5) to calculate the $\beta$-phase fraction transformation during the heating process. Figure 7 represents the correct $\beta$-phase fraction evolution, taking the initial phase fraction into account. 
It is well known that the Ti-6Al-4V alloy is stable until it reaches moderate temperatures $\left(400^{\circ} \mathrm{C}\right)$, and this can be observed on the dilatometry curve. Indeed, Figure 7 shows the beginning of the $\alpha / \beta$ transformation at $500^{\circ} \mathrm{C}$ and the $\beta$-transus occurring at $980^{\circ} \mathrm{C}$, a value close to the $973^{\circ} \mathrm{C}$ noted on the product certification. These results validate the experiment and the calculation of the $\beta$-phase fraction.

Once the relationship between the temperature and phase fraction transformation had been plotted, three heat treatments were chosen to represent the total $\alpha^{\prime}$-phase region (from $900^{\circ} \mathrm{C}$ to $\beta$-transus temperature [14]).

The microstructure of the different heat-treated samples was analysed by SEM using a BSE detector, which identifies the chemical difference between the $\alpha^{\prime}$-phase and $\alpha$ phase. The resulting images and the initial microstructure are presented in Figure 6 . The phase fraction was evaluated using image software analysis. Comparative values are given in Table 2.

The differences observed between the two techniques may be due to the heating rate. It was previously reported by J.W. Elmer et al. that the heating rate influences the phase fraction transformation in Ti-6Al-4V alloy [15]. Their study shows that an increase in the heating rate decreases the percentage of the transformed $\beta$-phase for a given temperature. In the present study, 51 minutes were needed to reach a temperature of $1030^{\circ} \mathrm{C}$ in the dilatometry test carried out at $20^{\circ} \mathrm{C} / \mathrm{min}$, while the same temperature was reached in under $15 \mathrm{~min}$ in the muffle furnace, as the $100 \% \alpha^{\prime}$ alloy microstructure shows. The higher heating rate on the muffle furnace therefore explained the lower values of phase transformation compared to those obtained from the dilatometry test. Below, the different samples will be referred to by their martensitic phase fraction, calculated by SEM microstructure analysis.

The activation energy of the grain growth $(Q)$ is calculated to identify how the main alloying elements influence the $\alpha / \beta$ transformation during holding. In Figure 8 , the $\beta$ grain size (measured from SEM images) is represented according to the holding temperature.

Basic calculations predicting the grain size are based on the equation for ideal grain growth, see Equation 1:

$$
D-D_{0}=K t^{n}
$$


where $D$ is the actual grain size, $D_{0}$ is the initial grain size at the considered temperature; $K$ is the proportional constant, $t$ is the holding time at the temperature and $n$ is its exponent $(n=1)$. This equation presumes the absence of defects and precipitates and supposes that grain growth is controlled by diffusion alone.

Although this equation represents an isothermal condition, the relative rapidity of the heating stage would logically limit any growth during heating. $D_{0}$ can therefore be considered as the grain size of the initial material state at room temperature.

Equation 2, or the Arrhenius equation, defines the relation between the proportionality constant $K$ and temperature $T$ at which the grain grows.

$$
K=K_{0} \exp \left(-\frac{Q}{R T}\right)
$$

In Equation 2, $T$ is the holding temperature, $Q$ is the activation energy necessary for grain growth, $K_{0}$ is the total pre-exponential constant and $R$ is the gas constant.

The proportional constant $K$ can be calculated from Equation 1 before being applied to Equation 1 to identify the activation energy $(Q)$ value through a linear regression line.

The activation energy value obtained is $176 \mathrm{KJ} / \mathrm{mol}$; this is close to the value of $173.3 \mathrm{KJ} / \mathrm{mol}$ found in the literature for vanadium diffusion in titanium [16]. This result leads to the conclusion that the $\alpha$ to $\beta$ transformation is governed by the diffusion of vanadium.

To obtain a better insight into the transformation phase resulting from heat treatments, XRD analysis was carried out on the initial and heat-treated samples. The results are presented in Figure 9.

One example of $\beta / \alpha^{\prime}$ martensitic transformation is the disappearance of the initial $\beta$ phase in the heat-treated samples. This is clearly seen in the different diffractograms. The lattice parameters of the $\alpha$-phase and $\alpha^{\prime}$-phase can be observed on the $\alpha+\alpha^{\prime}$ samples in the form of double peaks in the initial $\alpha$-phase peak. The evolution of these parameters is also observed on the heat-treated samples, mainly thought to be due to their chemical evolution (vanadium diffusion).

The XRD diffractograms were used to calculate the lattice parameters of the initial and heat-treated alloys. Table 3 shows the different values of the $\alpha$-phase and $\alpha$-phase. 
Different studies report varying $\alpha$-phase lattice parameters values $[17,18]$. Our findings are in accordance with those of R. Montanari et al. [19].

When the heat treatment temperature increases, a decrease occurs in $\mathrm{a}_{0}$ as well as $\mathrm{c}_{0}$ from the $\alpha$-phase. This is the result of the heat-induced evolution in the chemical composition.

A semi-quantitative evaluation using the SEM-EDX technique was carried out to evaluate this hypothesis. Results are given in Figure 10.

In order to preserve this phase at room temperature, the vanadium content observed in the initial $\beta$-phase must remain high [20]. When the temperature increases, the $\beta$ phase fraction increases and its vanadium content decreases. At $47 \%$ of the transformation, the vanadium content is not high enough to form the secondary martensite ( $\alpha^{\prime \prime}$-phase) [21] or to retain the $\beta$-phase. Therefore, $\alpha^{\prime}$ martensite should form after all heat-treated alloys have been quenched. The chemical differences between the $\alpha$ - and $\alpha^{\prime}$-phases are responsible for the double peak appearance observed in the XRD results.

The first attempt to observe the influence of the different martensite fractions on mechanical properties was made using Vickers micro-hardness characterization. As the 'soft' $\beta$-phase [22] transformed into the martensitic $\alpha$ '-phase, we expected to observe a proportional increase in hardness as the martensite phase fraction increased. The microhardness of the different samples is presented in Figure 11.

For the high $\alpha^{\prime}$-phase fraction, the expected trend is observed. However, no difference in terms of hardness can be seen between the $47 \% \alpha^{\prime}$ sample and the initial sample. This may be due to the occurrence of a contra-balance effect, by which the hardness of the $\alpha^{\prime}$-phase is then decreased by the presence of the $\alpha$-phase through its lower vanadium content or by a TRIP effect. This point will be discussed later in the manuscript.

Tensile tests were performed to obtain a better understanding of the resulting mechanical properties. Figure 12 presents the resulting tensile curves for all studied alloys. The average value of the principal tensile properties is given in Table 4 .

Increasing the percentage of the martensitic $\alpha^{\prime}$-phase fraction leads to an increase in the UTS (Ultimate Tensile Strength). For higher $\alpha$-phase fractions (77\% and 100\%) the $\mathrm{YS}_{0.2}$ (Yield Strength) also increases significantly. However, a concurrent decrease is observed in the $\varepsilon_{\mathrm{u}}$ (Uniform Elongation). 
The tensile tests agree with previous results for hardness. The $47 \% \alpha^{\prime}$ sample possesses an unexpected mechanical behaviour, displaying an increase in $\varepsilon_{\mathrm{u}}$ while the $\mathrm{YS}_{0.2}$ remains at its initial $\alpha+\beta$ value.

Previous reports suggest the possibility of a TRIP deformation mechanism [9, 23] that could explain the abnormal behaviour of the $47 \% \alpha^{\prime}$ alloy. To verify if a phase transformation occurs during deformation, the work-hardening value has been calculated and is presented in Figure 13.

Improved work hardening is obtained in the $47 \% \alpha^{\prime}$ alloy, however no clear sign of the TRIP effect is observed. Thus, we can conclude that the behaviour of the $47 \% \alpha^{\prime}$ alloy is not due to the TRIP effect.

In agreement with C. Formanoir et al., the abnormal behaviour of the $47 \% \alpha^{\prime}$ alloy and its improved work-hardening could be due to a composite effect [10]. Some multiphase alloys may display unexpected work-hardening property when compared to their equivalent single-phase alloys. The work-hardening improvement can be attributed to the difference in mechanical properties between phases ( $\alpha$ - and $\alpha^{\prime}$-phase in this case). The consequently unequal distribution of stress and strain leads to the formation of additional dislocations at the interface, thus improving the global work hardening. TEM observations have been carried out on the sample, but due to a low statistic no clear evidence of this increase of dislocation density can be given.

As observed in DP steels, the inhomogeneity of mechanical properties between phases is due to their chemical composition. The work hardening improvement is therefore also related to the amount of martensite in the phase fraction.

The inhomogeneous deformation of the two phases ( $\alpha$ - and $\alpha^{\prime}$-phase) is shown in Figure 14 via Jaoul-Crussard plot analysis. Only three stages can be seen on the $47 \%$ $\alpha$ alloy:

1. Stage I - Homogenous elastic deformation of the $\alpha$ - and $\alpha^{\prime}$-phase.

2. Stage II - Inhomogeneous plastically deformation of the $\alpha$ - and $\alpha^{\prime}$-phase.

3. Stage III - Homogeneous plastically deformation of the $\alpha$ - and $\alpha^{\prime}$-phase.

In contrast to DP steels, the mechanical inhomogeneity of the $\alpha$ - and $\alpha^{\prime}$-phase in the studied alloys is much lower. When the percentage of phase fractions turns out to be 
dissimilar and martensite becomes the matrix, the work-hardening improvement is lost. Evidence of this is seen in the previous Jaoul-Crussard plot (Figure 14).

The low yield strength properties and micro-hardness presented by the $47 \% \alpha^{\prime}$ alloy may be due to the presence of very low and local fractions of the soft martensite $\alpha$ "phase or the retained $\beta$-phase, although no evidence of this was observed. Indeed, the low fraction of these phases involves using synchrotron diffraction to be possibly measured.

The most important mechanical property of any material subjected to repetitive loads is endurance, or fatigue strength. The results of the rotating bending fatigue tests performed on the initial and heat-treated samples are presented in Fiure 15.

The initial alloy (equiaxed $\alpha+\beta$ of this study) shows higher fatigue resistance than the values reported in previous literature, which range from $423-550 \mathrm{MPa}$ for Ti-6Al$4 \mathrm{~V}$ ELI grade during rotating bending fatigue tests $[24,6]$. This could be explained by different factors such as chemical impurities or microstructure size.

As observed in this study, all martensite alloys exhibit improved fatigue strength at $10^{7}$ cycles compared to the initial condition. The best fatigue performance is obtained in both $47 \%$ and $77 \%$ ' alloys, with a $20 \%$ increase in the initial fatigue strength, followed closely by the full martensitic alloy.

Results show no difference between alloys in terms of fatigue crack initiation, which first occurs at the surface of the sample where the stress is higher.

The improvement in fatigue properties has previously been attributed to a possible transformation-induced plasticity (TRIP) effect [9, 23], where energy dissipation may take place instead of the fatigue damage accumulation. However, none of the martensitic alloys in this work displayed any TRIP behaviour.

The fatigue improvement of the $47 \% \alpha^{\prime}$ alloy is mainly due to its improved workhardening and better accommodation of local dislocations during deformation. The improvement observed for the $77 \% \alpha^{\prime}$ alloy is mainly due to the yield strength increase and its relatively good ductility. The increase in yield strength in our study is reflected by an increase in its high cycle fatigue properties, supporting G. Lutjering's claim that there is a link between yield strength and fatigue life at high number of cycles [22]. A possible effect of the different texture obtained after the heat treatment can also be part of the explanation, as G. Lutjering already mentioned in his work. However, as the 
phases and a fraction of the phase are different in each of the case presented here, the effect of texture can be determined separately. It is worth mentioning that the other parameters known to modify the fatigue strength (iron composition, inclusions...) are the same in all the samples considered here.

From an industrial point of view, the large fraction range of $\alpha^{\prime}$-martensite over which optimal fatigue properties can be obtained makes water-quench heat treatment an ideal process for increasing the mechanical properties of Ti-6Al-4V and its ELI grade. It is always difficult to compare values with those found in literature, and this is especially true of titanium alloys, where impurities are so influential. For this reason, we prefer to compare the percentage of improvement rather than provide a precise fatigue value.

The most competitive technique permits the obtaining of a UFG microstructure. The martensitic alloy values of this study were compared to the fatigue strength of the microstructures (obtained from a rotating bending fatigue test) resulting from two different studies by S. Zherebtsov et. al, who obtained an improvement of $15 \%$ using multiaxial forging [25], and L.R. Saitova et. al, who obtained an improvement of 9\% using the ECAP process [6].

The water-quench heat-treatment is a more efficient and better technique to improve the mechanical properties of the Ti-6Al-4V ELI alloy: this process is not only remarkably simple in comparison with the complex process required by UFG methods, but also provides improved fatigue strength.

The cytotoxicity of these microstructures must be evaluated prior to their use for biomedical applications. In vitro cytotoxicity tests are the primary biocompatibility tests, as they can provide rapid and inexpensive data on biological interactions. The assay is related to the cell's viability and proliferation in the culture, generating a signal that is proportional to the number of living cells [26].

A toxic material is defined as a material that releases a chemical in enough quantities to kill cells or drastic decrease cell proliferation, either directly or indirectly, by inhibiting key metabolic pathways by comparison with cell culture on tissue culture treated plates [27].

The Ti-6Al-4V ELI grade has been used as a biomaterial for over a decade and is a leading structural material in the biomedical applications market. However, changes in microstructure and phase composition can affect its toxicity properties. 
Even if the cytotoxicity could depend on other aspects of the mierostructure (surface energy, crystallographic texture, grain boundary density, phase boundary density, surface topography...) in our case, we feel that the other parameters than composition are of second order. Indeed, most of the features of the microstructure will not change drastically between the samples. Surface topology is erased by polishing whereas surface energies should not change in that range of composition. In this study, cytotoxicity was evaluated in one of the various studied microstructures. Important factors as: surface energy [37,41,42], topography [32-40] or crystallographic texture [29-31] are not analysed in this study, even if they could influence the cytotoxicity results. The main objective of the experiment is to verify that the good cytotoxicity of the reference material is not degraded by the heat treatment. Thus, the results presented here are mainly comparative ones. It shows that the optimized microstructure in terms of mechanical properties does not exhibit a deteriorated biocompatibility considering that all the others important parameters cited before did not change.

The cytotoxicity experiment was done through 'direct assays': cells were directly placed on the material inside a culture plate before being incubated with a culture medium. The $47 \% \alpha$ ' alloy, sample showing one of the best fatigue properties, was tested with human MG-63 osteoblast-like cells and fibroblasts at various intervals (3, 6 and 10 days). Results of the cell proliferation evolution over time for both assays are plotted in Figure 16.

The MG-63 osteoblast-like cell cytotoxicity assays show that the new microstructure has a very limited effect on cell proliferation, with a main value which decreases but remains within the standard deviation of the comparison data. The presence of the $47 \%$ $\alpha$ alloy in the fibroblasts assays seems to decrease the proliferation rate further, although cell proliferation does not cease and increases with time, albeit at a slower rate. It must be noted that fibroblast proliferation started also at day 3 and still increases with time. The heightened sensitivity to the presence of the $47 \% \alpha^{\prime}$ alloy for the fibroblasts may be explained by one of the following hypotheses:

1. Fibroblasts cells are primary cells and consequently more 'fragile' than the MG-63 osteoblast-like cells after several passages [28].

2. Fibroblasts cells needs longer time to adapt to the metal surface. 
These results clearly show that, on the alloy considered here with this method, no cytotoxicity can be observed due to the presence of the $\alpha$ '-phase. We can conclude that the Ti-6Al-4V ELI grade, with the presence of a high fraction $\alpha^{\prime}$-martensite phase, is not cytotoxic. However, it is certain that further studies, such as in vivo assays, must be carried out to assess the safety of the heat treatments considered in this study.

\section{Conclusions}

This paper reports the use of a water-quench rapid heat treatment to optimize the microstructure and increase the mechanical properties of the Ti-6Al-4V ELI alloy currently used in biomedical applications.

The partial or total transformation of the Ti-6Al-4V ELI microstructure into a martensitic $\alpha^{\prime}$-phase improves the high cycle $\left(10^{7}\right.$ cycles $)$ fatigue strength when compared to the initial $\alpha+\beta$ equiaxed microstructure (Ti-6Al-4V ELI standard microstructure for biomedical applications).

Tensile test results reveal an unexpected behaviour of the $47 \% \alpha^{\prime}$ alloy. An increase in ductility is observed, whilst the same yield strength value as the initial condition is maintained. This phenomenon may possibly be related to a 'composite effect' resulting from a difference in the chemical compositions of the $\alpha$ and $\alpha$ ' phases.

The optimum fatigue performance is located within in a wide phase fraction range ranging from $47 \%$ to $77 \% \alpha^{\prime}$-phase, making the water-quench heat treatment an economic and efficient technique. The martensitic alloys remain cytocompatibility with the initial $\alpha+\beta$ microstructure, which is currently used in biomedical applications.

The results presented show that martensitic dual phase $(\alpha+\beta)$ Ti-6Al-4V ELI alloys can be proposed as a new standard in biomedical applications. Indeed, heat treatment improves the static and fatigue properties of these microstructures without modifying the cytotoxicity of the alloy.

\section{$440 \quad$ References}

[1] Bothe, R. T. (1940). Reaction of bone to multiple metallic implants. Surg Gynecol Obstet, 71, 598-602. 
[2] Leventhal, G. S. (1951). Titanium, a metal for surgery. J Bone Joint Surg Am, 33(2), 473-474.

[3] Beder, O. E., \& Eade, G. (1956). An investigation of tissue tolerance to titanium metal implants in dogs. Surgery, 39(3), 470-473.

[4] A. Standard, F136-02a: Standard speciation for wrought titanium-6 aluminum-4 vanadium Eli (extra low interstitial) alloy for surgical implant applications (uns r56401). west Conshohocken, pa: Astm international; 2002, doi: 10.1520/f0136-02a, West Conshohocken, PA: ASTM International.

[5] Saitova, L. R., Höppel, H. W., Göken, M., Semenova, I. P., \& Valiev, R. Z. (2009). Cyclic deformation behavior and fatigue lives of ultrafine-grained Ti6AL-4V ELI alloy for medical use. International Journal of Fatigue, 31(2), 322-331.

[6] Saitova, L. R., Höppel, H. W., Göken, M., Semenova, I. P., Raab, G. I., \& Valiev, R. Z. (2009). Fatigue behavior of ultrafine-grained Ti-6Al-4V 'ELI'alloy for medical applications. Materials Science and Engineering: A, 503(1-2), 145-147.

[7] Zherebtsov, S., Kudryavtsev, E., Kostjuchenko, S., Malysheva, S., \& Salishchev, G. (2012). Strength and ductility-related properties of ultrafine grained two-phase titanium alloy produced by warm multiaxial forging. Materials Science and Engineering: A, 536, 190-196.

[8] Sherman, R. G., \& Kessler, H. D. (1956). Investigation of the heat treatability of the $6 \%$ aluminum- $4 \%$ vanadium titanium based alloy. Trans ASM, 48, 657676.

[9] Imam, M. A., \& Gilmore, C. M. (1983). Fatigue and microstructural properties of quenched Ti-6Al-4V. Metallurgical Transactions A, 14(1), 233-240.

[10] de Formanoir, C., Brulard, A., Vivès, S., Martin, G., Prima, F., Michotte, S., ... \& Godet, S. (2017). A strategy to improve the work-hardening behavior of Ti-6Al-4V parts produced by additive manufacturing. Materials Research Letters, 5(3), 201-208. 
[11] Matsumoto, H., Yoneda, H., Fabregue, D., Maire, E., Chiba, A., \& Gejima, F. (2011). Mechanical behaviors of Ti-V-(Al, Sn) alloys with $\alpha^{\prime}$ martensite microstructure. Journal of Alloys and Compounds, 509(6), 2684-2692.

[12] Matsumoto, H., Yoneda, H., Sato, K., Kurosu, S., Maire, E., Fabregue, D., ... \& Chiba, A. (2011). Room-temperature ductility of Ti-6Al-4V alloy with $\alpha^{\prime}$ martensite microstructure. Materials Science and Engineering: A, 528(3), $1512-1520$.

[13] Kahveci, A. I., \& Welsch, G. E. (1986). Effect of oxygen on the hardness and alpha/beta phase ratio of Ti-6A1-4V alloy. Scripta metallurgica, 20(9), 12871290.

[14] Welsch, G., Boyer, R., \& Collings, E. W. (Eds.). (1993). Materials properties handbook: titanium alloys. ASM international.

[15]Elmer, J. W., Palmer, T. A., Babu, S. S., \& Specht, E. D. (2005). Low temperature relaxation of residual stress in Ti-6Al-4V. Scripta materialia, 52(10), 1051-1056.

[16]E. A. Brandes, G. Brook, Smithells materials reference book (1992).

[17] Grabovetskaya, G. P., Melnikova, E. N., Kolobov, Y. R., Chernov, I. P., Naidenkin, E. V., Nikitenkov, N. N., \& Mishin, I. P. (2006). Evolution of the structural and phase states of a Ti-6Al-4V alloy in forming submicrocrystalline structure with the use of temporary hydrogenation. Russian Physics Journal, 49(4), 442-447.

[18] Ivanov, M. B., Manokhin, S. S., Kolobov, Y. R., \& Nechayenko, D. A. (2010). Phase composition and microstructure of Ti-6Al-4V alloy after hydrogenplastic working.

[19] Montanari, R., Costanza, G., Tata, M. E., \& Testani, C. (2008). Lattice expansion of $\mathrm{Ti}-6 \mathrm{Al}-4 \mathrm{~V}$ by nitrogen and oxygen absorption. Materials characterization, 59(3), 334-337. 
[21] Bagariatskii, I. A., Nosova, G. I., \& Tagunova, T. V. (1958, September). Factors in the formation of metastable phases in titanium-base alloys. In Soviet Physics Doklady (Vol. 3, p. 1014).

[22]Lütjering, G. E. R. D. (1998). Influence of processing on microstructure and mechanical properties of $(\alpha+\beta)$ titanium alloys. Materials Science and Engineering: A, 243(1-2), 32-45.

[23] Kennedy, J. R. (1983). Fatigue behavior of solution-treated and quenched Ti6Al-4V. Materials Science and Engineering, 57(2), 197-204.

[24] Niinomi, M. (2007). Fatigue characteristics of metallic biomaterials. International Journal of Fatigue, 29(6), 992-1000.

[25]Zherebtsov, S., Salishchev, G., Galeyev, R., \& Maekawa, K. (2005). Mechanical properties of Ti-6Al-4V titanium alloy with submicrocrystalline structure produced by severe plastic deformation. Materials transactions, 46(9), 2020-2025.

[26] Mosmann, T. (1983). Rapid colorimetric assay for cellular growth and survival: application to proliferation and cytotoxicity assays. Journal of immunological methods, 65(1-2), 55-63.

[27] Ratner, B. D., Hoffman, A. S., Schoen, F. J., \& Lemons, J. E. (2004). Biomaterials science: an introduction to materials in medicine. Elsevier.

[28] Cristofalo, V. J., Allen, R. G., Pignolo, R. J., Martin, B. G., \& Beck, J. C. (1998). Relationship between donor age and the replicative lifespan of human cells in culture: a reevaluation. Proceedings of the National Academy of Sciences, 95(18), 10614-10619.

[29] S. Faghihi et al., "The significance of crystallographic texture of titanium alloy substrates on pre-osteoblast responses," Biomaterials, vol. 27, pp. 3532-3539, 2006.

[30] S. Faghihi, H. Vali, and M. Tabrizian, "Effects of crystal size and orientation of substrates on cell adhesion: Implication for medical implants,” Int. J. Mod. Phys. B, vol. 22, no. 18-19, pp. 3069-3081, 2008. 
[31] S. Faghihi, M. R. Bateni, F. Azari, J. A. Szpunar, H. Vali, and M. Tabrizian, "The Role of Crystallographic Texture of Ti-6Al-4V Alloy on Cell Attachment and Proliferation," Mater. Sci. Forum, vol. 495-497, pp. 705-710, 2005.

[32] C. H. Lohmann et al., "Surface roughness modulates the response of MG63 osteoblast-like cells to 1,25-(OH)2D3 through regulation of phospholipase A2 activity and activation of protein kinase A," J. Biomed. Mater. Res., vol. 47, no. 2, pp. 139-151, Nov. 1999.

[33] R. A. Gittens et al., "The effects of combined micron-/submicron-scale surface roughness and nanoscale features on cell proliferation and differentiation," Biomaterials, vol. 32, no. 13, pp. 3395-3403, 2011.

[34] R. A. Gittens et al., "A review on the wettability of dental implant surfaces II: Biological and clinical aspects," Acta Biomaterialia, vol. 10, no. 7. 2014.

[35] A. Iost, D. Najjar, K. Anselme, and M. Bigerelle, "Relationships between the surface morphology and a physical response in the biomaterial field," in Thermec'2003, Pts 1-5, vol. 426-4, T. Chandra, J. M. Torralba, and T. Sakai, Eds. Zurich-Uetikon: Trans Tech Publications Ltd, 2003, pp. 3031-3036.

[36]K. Anselme and M. Bigerelle, "Modelling approach in cell/material interactions studies," Biomaterials, vol. 27, no. 8, pp. 1187-1199, 2006.

[37] G. Zhao, A. L. Raines, M. Wieland, Z. Schwartz, and B. D. Boyan, "Requirement for both micron- and submicron scale structure for synergistic responses of osteoblasts to substrate surface energy and topography," Biomaterials, vol. 28, no. 18, pp. 2821-2829, 2007.

[38] K. M. Hotchkiss, G. B. Reddy, S. L. Hyzy, Z. Schwartz, B. D. Boyan, and R. Olivares-Navarrete, "Titanium surface characteristics, including topography and wettability, alter macrophage activation," Acta Biomater., vol. 31, 2016.

[39] R. A. Gittens et al., "The roles of titanium surface micro/nanotopography and wettability on the differential response of human osteoblast lineage cells," Acta Biomater., vol. 9, no. 4, 2013. 
[40] B. D. Boyan et al., "Osteoblast-Mediated Mineral Deposition in Culture is Dependent on Surface Microtopography," Calcif. Tissue Int., vol. 71, pp. 519$529,2002$.

[41] D. J. Irvine, K.-A. Hue, A. M. Mayes, and L. G. Griffith, "Simulations of CellSurface Integrin Binding to Nanoscale-Clustered Adhesion Ligands.”

[42] J. Luo and Y.-M. Chiang, "Existence and stability of nanometer-thick disordered films on oxide surfaces," Acta Mater., vol. 48, no. 18, pp. 45014515, 2000. 
Table 1: Chemical composition of the Ti-6Al-4V ELI alloy used in the present research [Wt.\%]

\begin{tabular}{rccccccc}
\hline Ti & Al & $\mathbf{V}$ & $\mathbf{C}$ & $\mathbf{F e}$ & $\mathbf{N}$ & $\mathbf{O}$ & $\mathbf{H}$ \\
\hline Bal. & 6.01 & 3.93 & 0.015 & 0.18 & 0.005 & 0.12 & 0.0025 \\
\hline
\end{tabular}

570

Table 2: SEM (BSE) and Dilatometry phase fraction calculation of the resulting $\alpha^{\prime}-$ martensite.

\begin{tabular}{ccc}
\hline Heat treatment & \multicolumn{2}{c}{$\boldsymbol{\alpha}$ 'fraction [\%] } \\
temperature $\left[{ }^{\circ} \mathbf{C}\right]$ & SEM $($ BSE) & Dilatometry \\
\hline 923 & 47 & 66 \\
948 & 77 & 87 \\
1030 & 100 & 100 \\
\hline
\end{tabular}

Table 3: Lattice parameters of $\alpha$-phase and $\alpha^{\prime}$-phase for the initial and heat-treated alloys.

\begin{tabular}{|c|c|c|c|c|}
\hline \multirow{2}{*}{$\boldsymbol{\alpha}^{\prime}$ fraction [\%] } & \multicolumn{2}{|c|}{$\boldsymbol{\alpha}$} & \multicolumn{2}{c|}{$\boldsymbol{\alpha}^{\prime}$} \\
\cline { 2 - 5 } & $\mathrm{a}_{0}[\mathrm{~nm}]$ & $\mathrm{c}_{0}[\mathrm{~nm}]$ & $\mathrm{a}_{0}[\mathrm{~nm}]$ & $\mathrm{c}_{0}[\mathrm{~nm}]$ \\
\hline Initial & 0.29336 & 0.46804 & & \\
\hline 47 & 0.29217 & 0.46657 & 0.29140 & 0.46357 \\
\hline 77 & 0.29194 & 0.46648 & 0.29134 & 0.46489 \\
\hline 100 & & & 0.29142 & 0.46576 \\
\hline
\end{tabular}

Table 4: Principal tensile properties from initial and heat-treated samples.

\begin{tabular}{ccccccccc}
\hline \multirow{2}{*}{$\boldsymbol{\alpha}^{\prime}$ fraction [\%] } & \multicolumn{2}{c}{$\mathbf{Y S}_{\mathbf{0 . 2}}$ [MPa] } & \multicolumn{2}{c}{$\mathbf{U T S}$} & \multicolumn{2}{c}{$\boldsymbol{\varepsilon}_{\mathbf{u}}[\boldsymbol{\%}]$} & $\mathbf{Y S}_{\mathbf{0 . 2}} / \boldsymbol{\varepsilon u}$ & $\mathbf{A}_{\mathbf{r}}[\%]$ \\
& & $S E_{X}$ & & $S E_{X}$ & & $S E_{X}$ & Ratio & \\
\hline Initial & 872 & 2 & 1076 & 9 & 8.1 & 0.3 & 108 & 30 \\
47 & 875 & 9 & 1140 & 1 & 10.3 & 0.8 & 85 & 68 \\
77 & 923 & 2 & 1131 & 6 & 5.7 & 0.5 & 100 & 37 \\
100 & 960 & 16 & 1122 & 6 & 4 & 0.4 & 204 & 30 \\
\hline
\end{tabular}




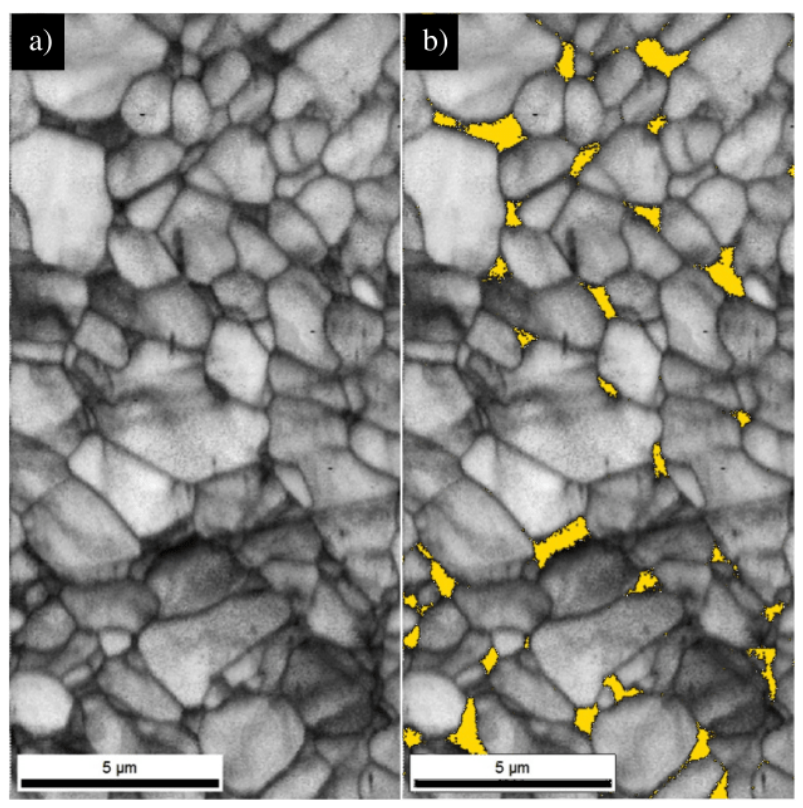

Figure 1: a) EBSD quality map of the initial microstructure. b) EBSD map with $\beta$ phase in yellow.

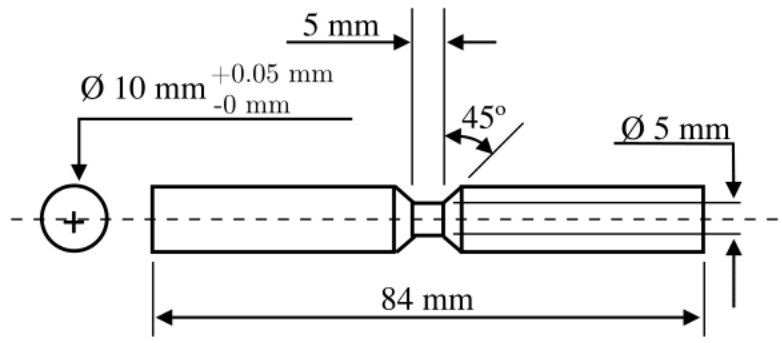

Figure 2: Sample design for dilatometry testing (dimensions in mm.).

590

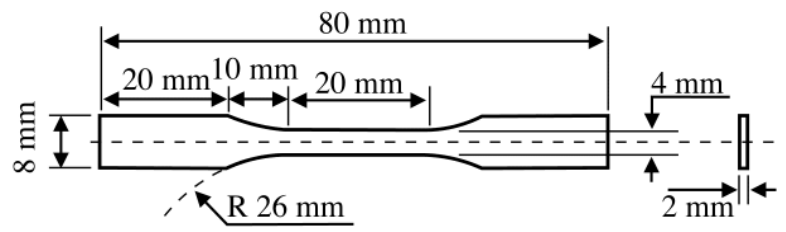

Figure 3: Sample design for tensile testing (dimensions in $\mathrm{mm}$.). 


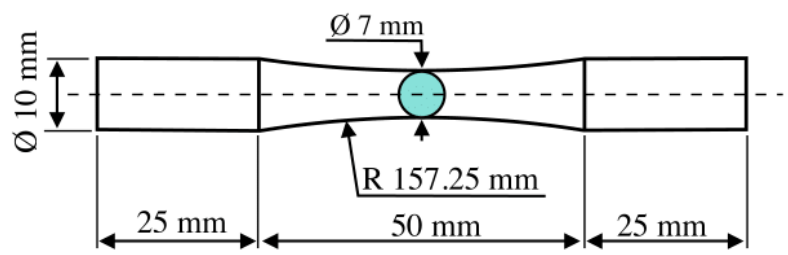

Figure 4: Sample design for rotating bending fatigue testing (dimensions in $\mathrm{mm}$.).

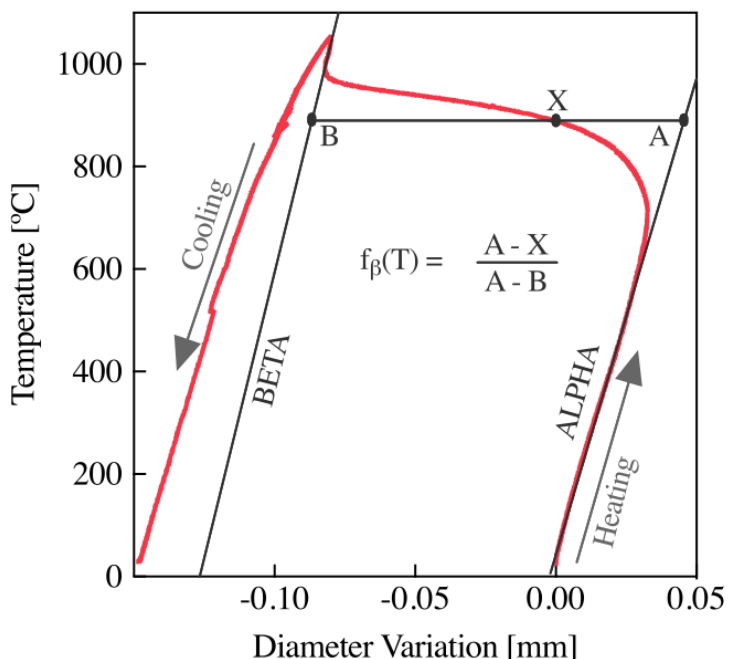

600

Figure 5: Dilatometry curve of the initial Ti-6AL-4V ELI alloy. 


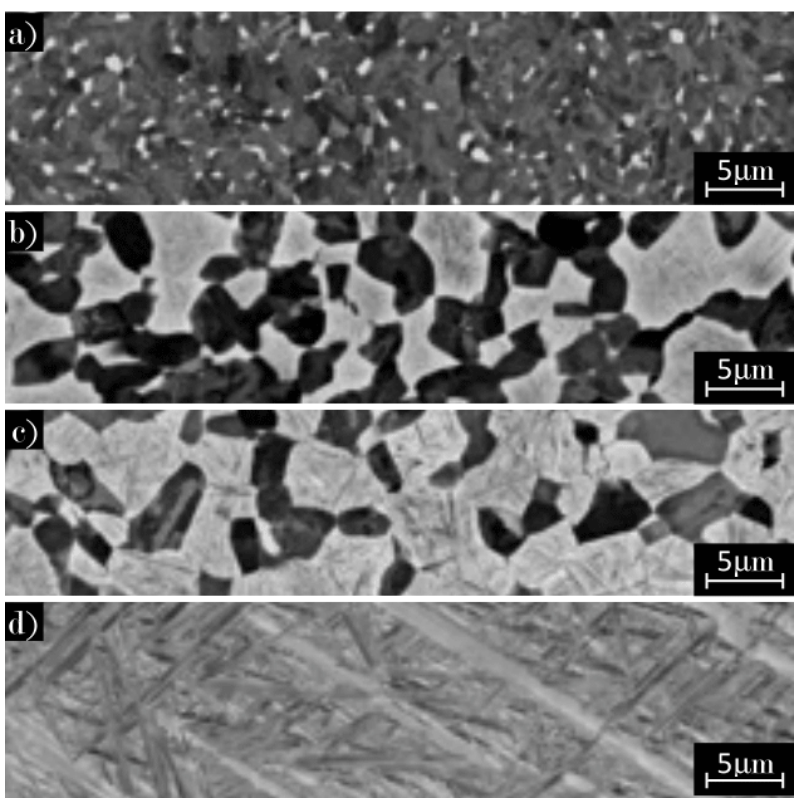

Figure 6: SEM (BSE) observation. a) Initial $\alpha+\beta$ microstructure ( $\beta$ in bright). b) and c) $923^{\circ} \mathrm{C}, 948^{\circ} \mathrm{C}$ WQ-HT dual $\alpha+\alpha$ microstructure respective (martensite in bright). d) $1030^{\circ} \mathrm{C} \mathrm{WQ-SHT}$ full $\alpha^{\prime}$ microstructure.

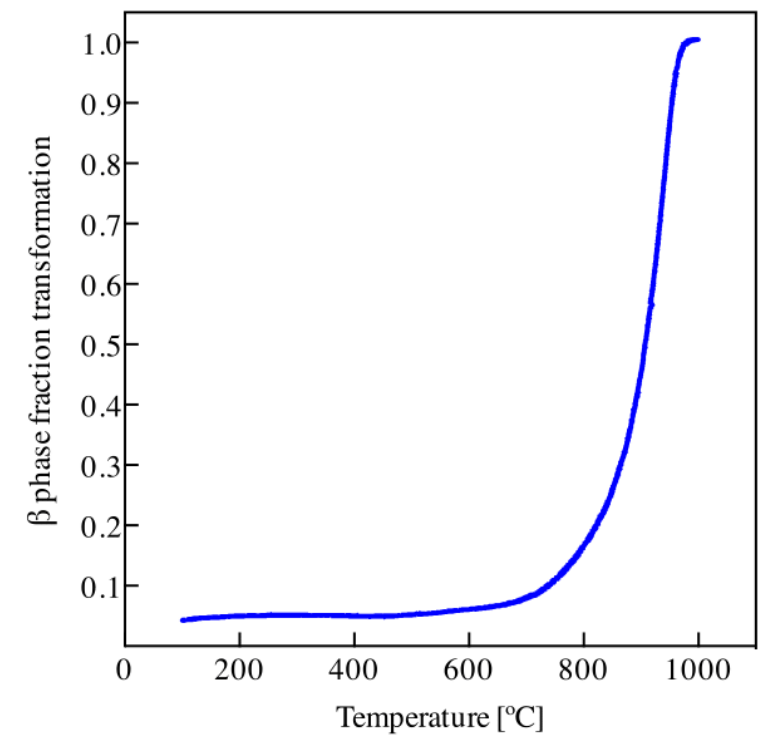

Figure 7: $\beta$-phase transformation during heating calculated from the dilatometry test. 


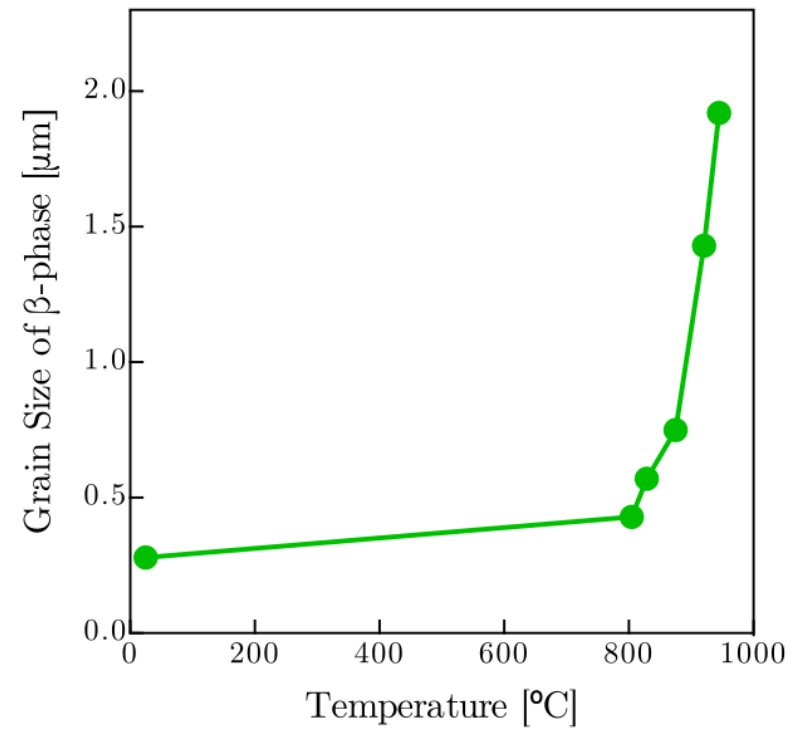

Figure 8: Grain size of $\beta$-phase as a function of holding temperature.

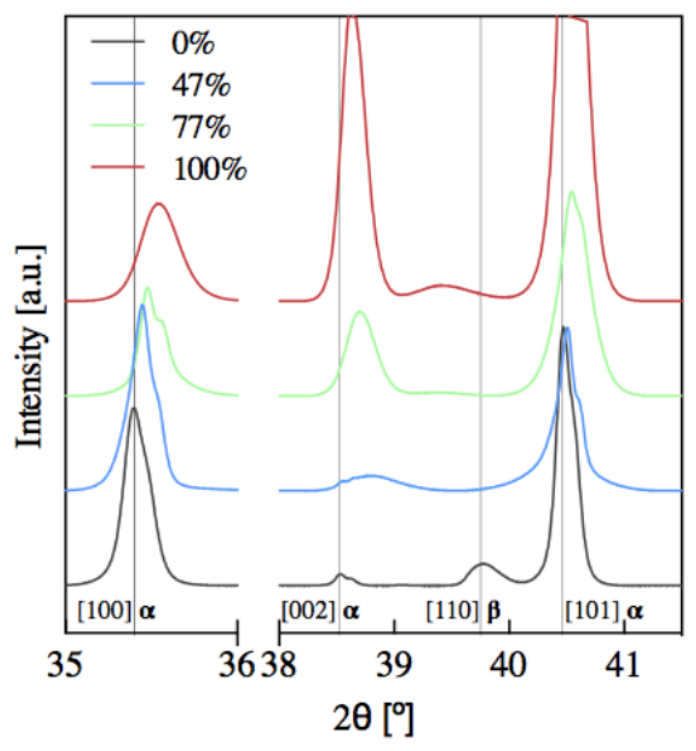

Figure 9: XRD diffractograms of the initial and different heat-treated samples. 
a)

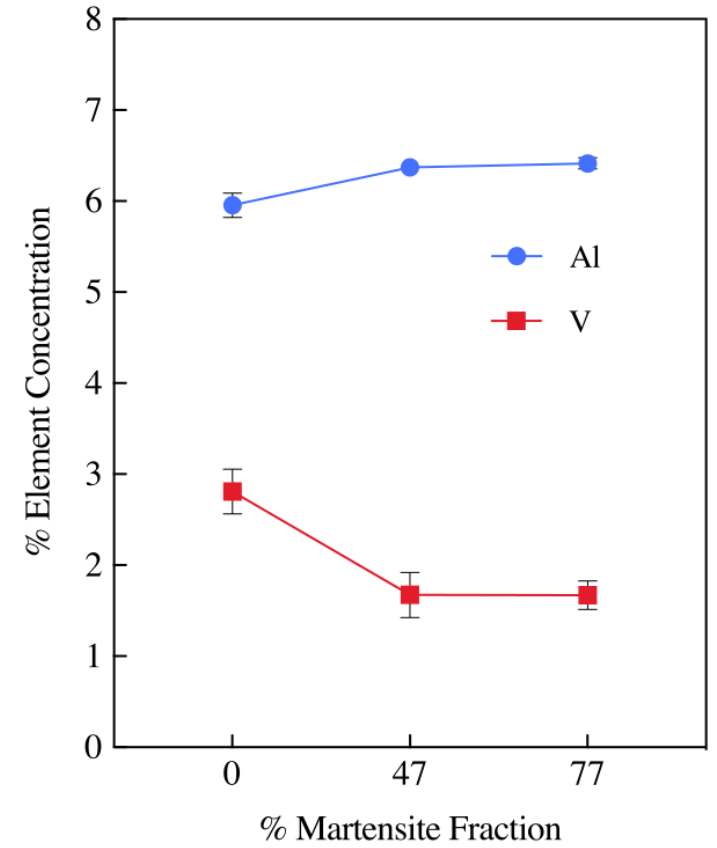

b)

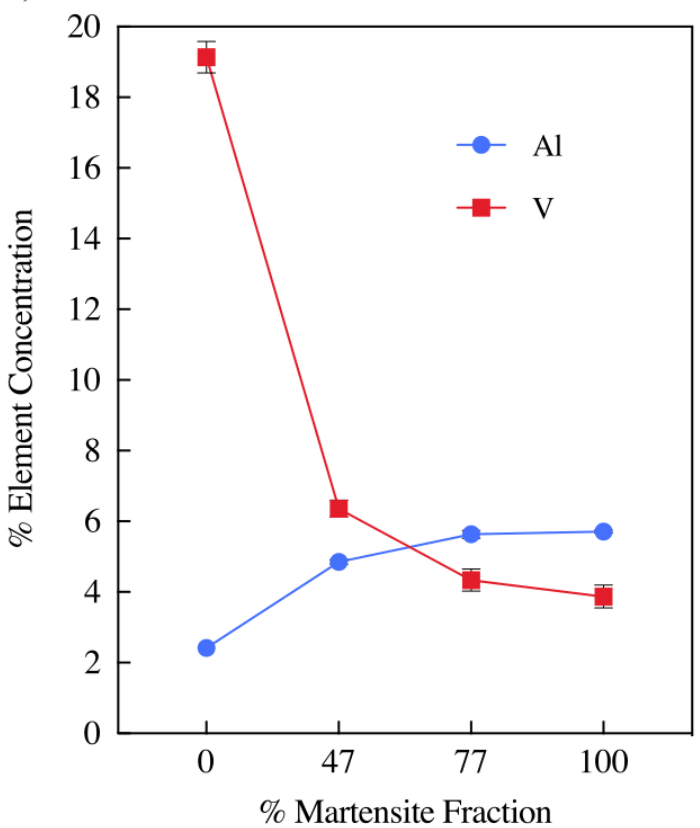

Figure 10: EDX-SEM composition of the main alloying elements in each phase. a) $\alpha$-phase. b) $\beta / \alpha^{\prime}$-phase. 


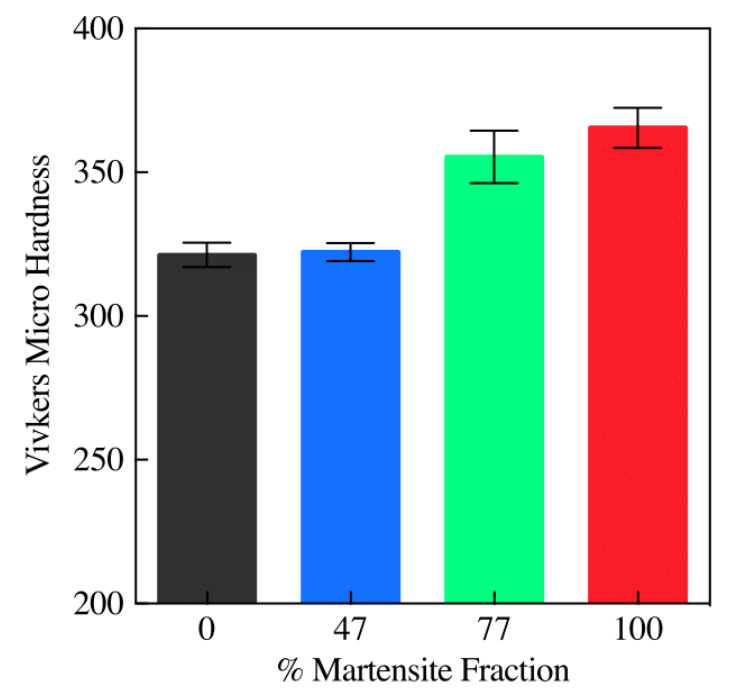

Figure 11: Vickers micro-hardness results for initial and different martensitic alloys.

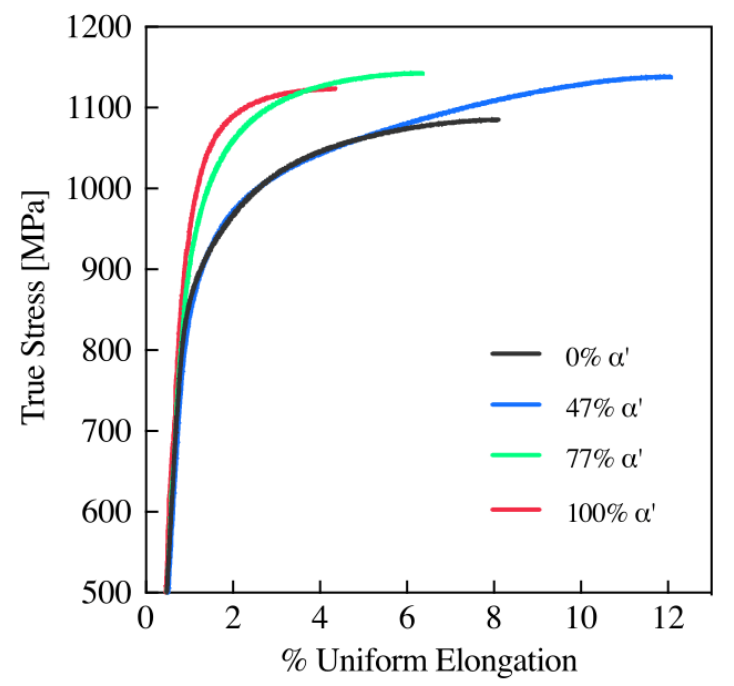

Figure 12: Tensile test curves for the initial and different martensitic alloys. 


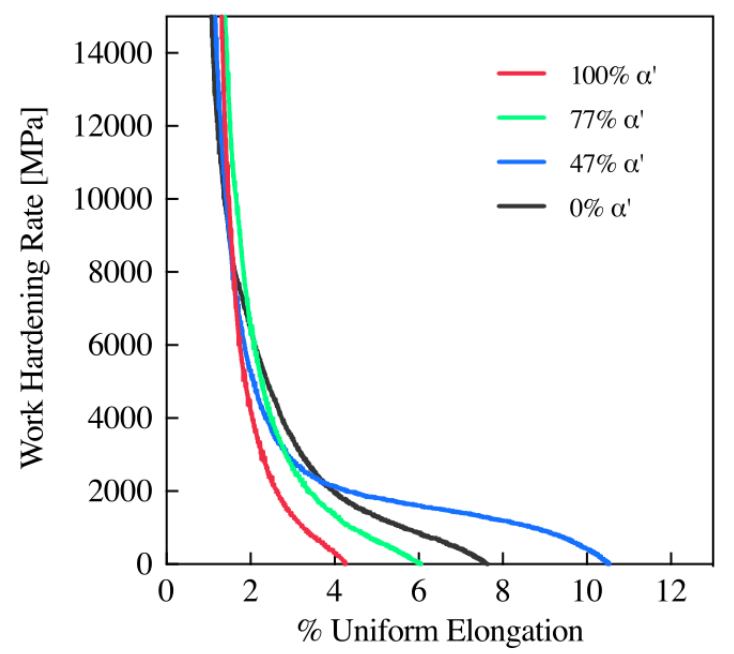

$630 \quad$ Figure 13: Work hardening rate curves of tensile testing for initial and different martensitic alloys.

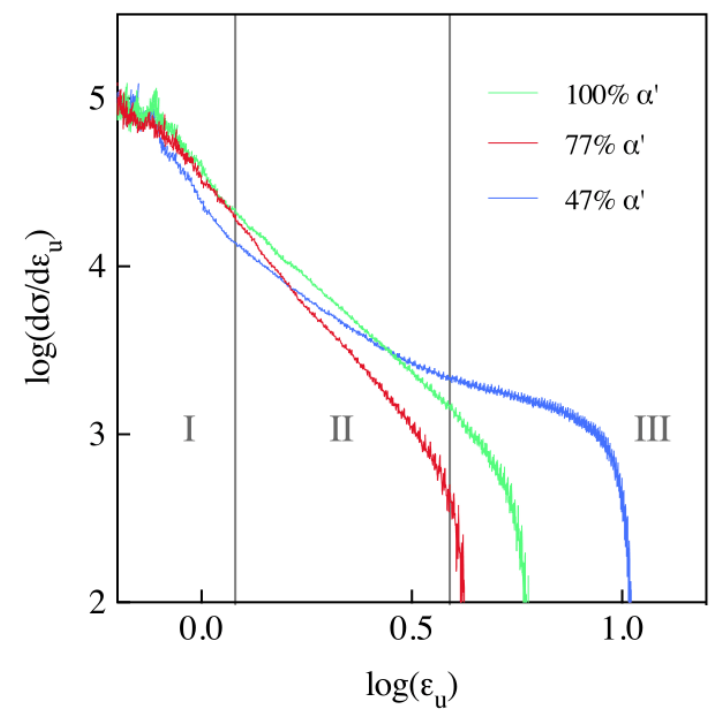

Figure 14: Jaoul-Crussard plot analysis of the heat-treated samples. 


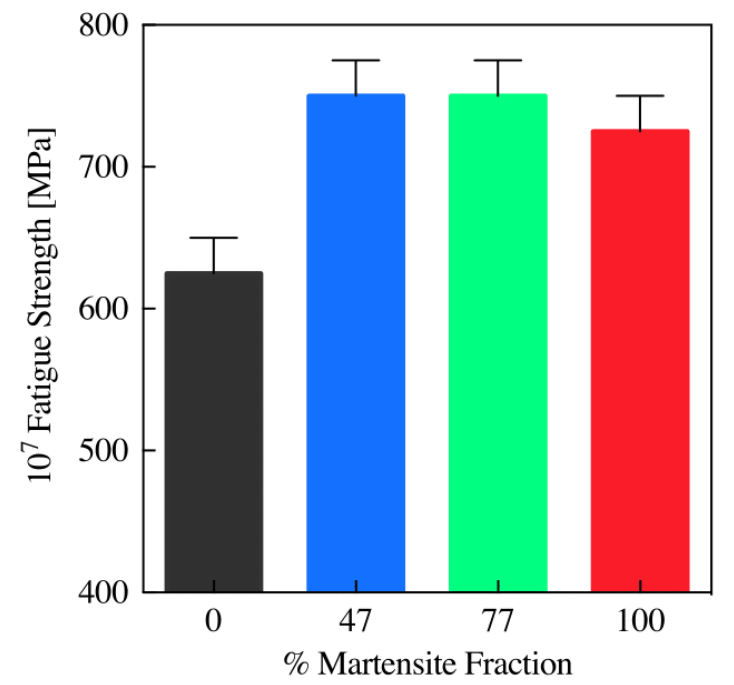

Figure 15: $10^{7}$ cycles fatigue life for the initial and different martensitic alloys.
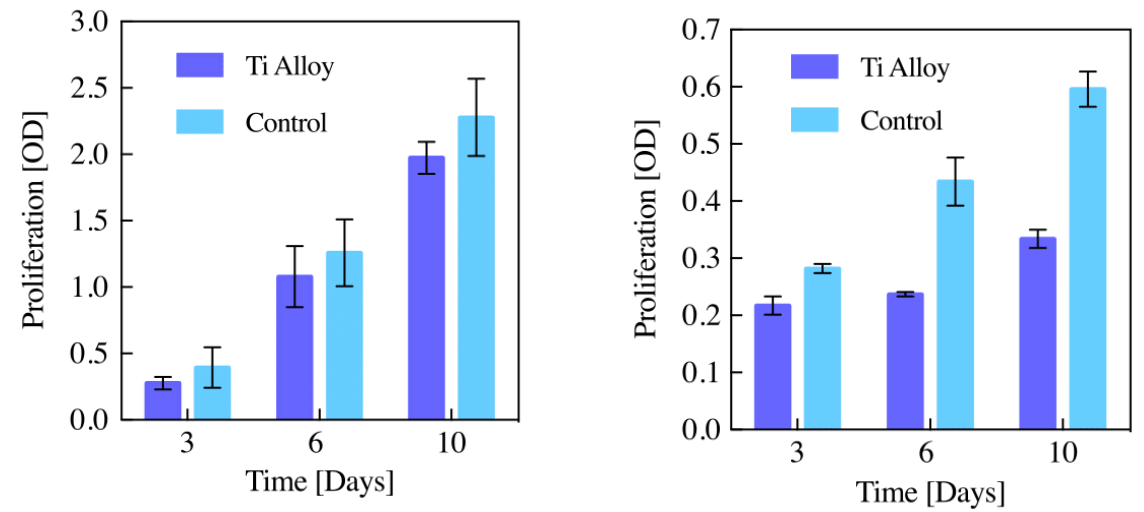

Figure 1: Cytotoxicity assays on the $47 \% \alpha$ ' alloy and culture treated polystyrene: LEFT) MG-63 osteoblast-like cells. RIGHT) Fibroblasts. (mean _ standard deviation). 